\title{
Highly Efficient Synthesis of 1-Thioamidoalkyl-2- naphthols and 14-Aryl-14H-dibenzo[a,j]xanthenes using a Novel Ionic Liquid: Catalyst Preparation, Characterization and Performing the Reactions
}

\author{
Atefeh Saadat, Abdolkarim Zare*, Fatemeh Jamadi, Maasoomeh Abdolalipour-Saretoli \\ Department of Chemistry, Payame Noor University, PO BOX 19395-3697, Tehran, Iran
}

Received: $21^{\text {st }}$ June 2017; Revised: $6^{\text {th }}$ October 2017; Accepted: $9^{\text {th }}$ October 2017;

Available online: $11^{\text {st }}$ June 2018; Published regularly: $1^{\text {st }}$ August 2018

\begin{abstract}
In this work, a novel Brønsted acidic ionic liquid namely triethylaminium- $\mathrm{N}$-sulfonic acid trifluoroacetate $\left\{[\right.$ TEASA] [TFA] $\}$ has been synthesized by the reaction of $\mathrm{NEt}_{3}$ with $\mathrm{ClSO}_{3} \mathrm{H}$, and then with $\mathrm{CF}_{3} \mathrm{CO}_{2} \mathrm{H}$. The ionic liquid has been characterized by studying its spectroscopic data $\left({ }^{1} \mathrm{H}\right.$ and ${ }^{13} \mathrm{C} N M R$, FT-IR, and mass spectra). Afterward, it has been utilized as a highly effective and general catalyst to promote the following organic reactions in solvent-free conditions: (i) the production of 1thioamidoalkyl-2-naphthols from arylaldehydes, 2-naphthol and thioacetamide, and (ii) the preparation of 14-aryl-14H-dibenzo[a,j]xanthenes from arylaldehydes and 2-naphthol. It is noteworthy that [TEASA][TFA] has catalyzed the reactions under milder conditions relative to most of the reported methods. Moreover, it afforded the both products in higher yields with respect to most of the previous works. Copyright (C) 2018 BCREC Group. All rights reserved
\end{abstract}

Keywords: Triethylaminium-N-sulfonic acid trifluoroacetate $\{[$ TEASA][TFA]\}; Brønsted acidic ionic liquid; 1-Thioamidoalkyl-2-naphthol; 14-Aryl-14H-dibenzo[a,j]xanthene

How to Cite: Saadat, A., Zare, A., Jamadi, F., Abdolalipour-Saretoli, M. (2018). Highly Efficient Synthesis of 1-Thioamidoalkyl-2-naphthols and 14-Aryl-14H-dibenzo[a,j]xanthenes using a Novel Ionic Liquid: Catalyst Preparation, Characterization and Performing the Reactions. Bulletin of Chemical Reaction Engineering \& Catalysis, 13 (2): 204-212 (doi:10.9767/bcrec.13.2.1280.204-212)

Permalink/DOI: https://doi.org/10.9767/bcrec.13.2.1280.204-212

\section{Introduction}

Ionic liquids are defined as compounds including cations and anions (i.e. salts) which melt at or below $100{ }^{\circ} \mathrm{C}$. These salts have attracted rising interest in the last decade, due to their unique properties, such as: high thermal and chemical stability, non-flammability, non-

* Corresponding Author.

E-mail: abdolkarimzare@pnu.ac.ir,

abdolkarimzare@yahoo.com (Zare, A.)

Telp: +98-21-23320000, Fax: +98-21-22455429 volatility, wide liquid-state temperature range, large electrochemical window, favorable salvation behavior, and ability to use as solvent, reagent and catalyst in organic synthesis [1-10]. Among the different kinds of ionic liquids, Brønsted acidic ones have been designed to replace solid acids and traditional mineral liquid acids to catalyze chemical transformations [3-10].

Performing chemical reactions under solventfree conditions is an important technique in green chemistry in which many compounds could be synthesized in an effective and environ- 
ment friendly manner. Solvent-free synthesis has several benefits compared with the classical synthetic methods; these advantages include: (i) safer reaction profile, (ii) higher yield of product, (iii) shorter reaction time, (iv) higher selectivity in many reactions, (v) easier workup, (vi) maximum incorporation of the reactants into the aim product, (vii) fewer energy requirement to promote reaction, (viii) prevention of using harmful solvents, and (ix) prevention or minimization of waste/by-products [1113].

The 1-thioamidoalkyl-2-naphthol derivatives are of significance as they can be readily converted to biologically important compounds namely $\gamma$-amino alcohols which show hypotensive, bradycardia, antipain, antibacterial, secretase inhibitory and notch-sparing activities [14-17]. The general method for synthesis of 1-thioamidoalkyl-2-naphthols involves the condensation reaction of arylaldehydes with 2-naphthol and thioacetamide in the presence of a catalyst [18-25]. In spite of high importance of this class of compounds, their production has been scarcely studied in the literature. Moreover, in most of the works, only a few numbers of these compounds have been prepared.

The synthesis of xanthene derivatives has received great attention for pharmacologists and organic chemists owing to possessing broad spectrum of biological and pharmaceutical activities, such as: antiviral, antibacterial and anti-inflammatory properties [26-28]. Moreover, these compounds can be applied as $\mathrm{pH}$ sensitive fluorescent materials for visualization of biomolecules, as sensitizers in photodynamic therapy, and in laser technology [29-31]. The general method for synthesis of 14-aryl-14Hdibenzo[a,j]xanthenes, as a significant class of xanthenes, involves the reaction of arylaldehydes with 2-naphthol in the presence of a catalyst [8,32-40].

In this research, first of all, preparation and characterization of a novel Brønsted acidic ionic liquid (triethylaminium- $N$-sulfonic acid trifluoroacetate $\left\{[\right.$ TEASA] [TFA] $\}$ ) using ${ }^{1} \mathrm{H}$ and ${ }^{13} \mathrm{C}$ NMR, FT-IR, and mass spectra have been reported. Then, application of the ionic liquid as a highly effective and general catalyst for the production of 1-thioamidoalkyl-2-naphthols and 14-aryl-14H-dibenzo[ $a, j]$ xanthenes has been reported.

It should be mentioned that we have previously used [TEASA][Cl] for the production of 1-thioamidoalkyl-2-naphthols (only three compounds) [21] and 14-aryl-14H-dibenzo[a,j] xanthenes [8]. Novelties of this work relative to our previous works [8,21] including: (i) introducing [TEASA][TFA] as a novel ionic liquid, and testing its catalytic performance for organic synthesis, (ii) performing the reactions in milder conditions (in our previous works, the synthesis of 1-thioamidoalkyl-2-naphthols and xanthenes has been carried out at 110 and 120 ${ }^{\circ} \mathrm{C}$, respectively; however, in this work, 1-thioamidoalkyl-2-naphthols and xanthenes have been prepared at 80 and $100{ }^{\circ} \mathrm{C}$, correspondingly), (iii) application of fewer catalyst amount for the 1-thioamidoalkyl-2-naphthols synthesis, (iv) obtaining excellent yields and shorter reaction times for 1-thioamidoalkyl-2naphthols, (v) systematic study for the 1-thioamidoalkyl-2-naphthols production (in our previous work, only three 1-thioamidoalkyl-2-naphthols have been prepared; but, in the presented work, twelve 1-thioamidoalkyl-2-naphthols have been synthesized, and effect of various electronattracting, halogens and electron-releasing groups on different positions of arylaldehydes on the reaction has been studied).

\section{Materials and Methods}

\subsection{Materials and measurements}

All chemicals were purchased from Merck or Fluka Chemical Companies. Dichloromethane was dried over sodium sulfate, distilled and stored over molecular sieves. All known compounds were identified by comparison of their melting points and spectral data with those reported in the literature. The melting points were recorded on a Büchi B-545 apparatus in open capillary tubes. Progress of the reactions was monitored by thin layer chromatography (TLC) using silica gel SIL G/UV 254 plates. The ${ }^{1} \mathrm{H}$ NMR $(300,400$ or $500 \mathrm{MHz})$ and ${ }^{13} \mathrm{C}$ NMR $(75,100$ or $125 \mathrm{MHz})$ were run on a Bruker Avance DPX, FT-NMR spectrometers. Mass spectra were obtained with Shimadzu GC-MS-QP 1100 EX model.

\subsection{Preparation of [TEASA][TFA]}

A solution of triethylamine $(0.50 \mathrm{~g}, 5 \mathrm{mmol})$ in dry dichloromethane $(20 \mathrm{~mL})$ was added dropwise to a stirring solution of chlorosulfonic acid $(0.58 \mathrm{~g}, 5 \mathrm{mmol})$ in dry dichloromethane $(20 \mathrm{~mL})$ over a period of $10 \mathrm{~min}$ at $10^{\circ} \mathrm{C}$. Afterward, the reaction mixture was heated to room temperature (accompanied with stirring), and stirred for another $4 \mathrm{~h}$. The solvent was evaporated, and the liquid residue was triturated with $t$-butylmethyl ether $(3 \times 10 \mathrm{~mL})$ and dried under powerful vacuum at $90{ }^{\circ} \mathrm{C}$ to give 
[TEASA][Cl] as a viscous pale yellow oil in $93 \%$ yield [8]. Then, trifluoroacetic acid $(0.570 \mathrm{~g}, 5$ mmol) was added dropwise to [TEASA][Cl] $(1.089 \mathrm{~g}, 5 \mathrm{mmol})$ over a period of $5 \mathrm{~min}$ at room temperature under pressure of nitrogen gas (to remove $\mathrm{HCl}$ produced during the reaction). The resulting mixture was stirred for 10 $\mathrm{h}$ at room temperature, and $2 \mathrm{~h}$ at $60^{\circ} \mathrm{C}$ under a continuous flow of nitrogen gas to give [TEASA][TFA] as a viscous pale yellow liquid. The spectroscopic data of [TEASA][TFA] include: IR (nujol, $\mathrm{cm}^{-1}$ ): 852, 1068, 1172, 1229, 1291, 1709, 2400-3600; ${ }^{1} \mathrm{H}$ NMR $(400 \mathrm{MHz}$, DMSO-d 6 ): $\delta$ (ppm) $1.21(\mathrm{t}, J=7.5 \mathrm{~Hz}, 9 \mathrm{H}), 3.10$ (q, $J=7.5 \mathrm{~Hz}, 6 \mathrm{H}$ ), 10.00 (br., $1 \mathrm{H}$ ); ${ }^{13} \mathrm{C}$ NMR (100 MHz, DMSO-d 6 ): $\delta$ (ppm) 8.7, 46.3, 115.4 (q), 158.8 (q); MS: $m / z 295\left(\mathrm{M}^{+}\right), 296\left(\mathrm{M}^{+}+1\right)$. These spectral data are in accordance with the literature $[8,9]$.

\subsection{General procedure for the synthesis of 1-thioamidoalkyl-2-naphthols}

A mixture of arylaldehyde (1 $\mathrm{mmol})$, 2-naphthol (1 mmol), thioacetamide $(1.2 \mathrm{mmol})$ and [TEASA][TFA] $(0.044 \mathrm{~g}, 0.15 \mathrm{mmol})$ was firstly stirred by a magnet at $80^{\circ} \mathrm{C}$, and after solidification of the reaction mixture, it was stirred with a small rod at the same temperature. The progress of the reaction was monitored by TLC) $n$-hexane/ethyl acetate: 3/1); after completion of the reaction, the mixture was cooled to room temperature, and recrystallized from hot ethanol (95\%) to give the pure product [18-25].

\subsection{General procedure for the production of 14 -aryl-14H-dibenzo[a,j]xanthenes}

A mixture of arylaldehyde (1 $\mathrm{mmol})$, 2-naphthol (2 mmol) and [TEASA][TFA] (0.044 $\mathrm{g}, 0.15 \mathrm{mmol}$ ) was initially stirred by a magnet at $100{ }^{\circ} \mathrm{C}$, and after the reaction was solidified, it was stirred with a small rod at that temperature. After the reaction was completed as monitored by TLC) $n$-hexane/ethyl acetate: $3 / 1)\}$, the mixture was cooled to room temperature, and the solid residue (crude product) was purified by recrystallization from hot ethanol (95\%) [8,32-40].

\section{Result and Discussion}

\subsection{Production and characterization of the catalyst}

In continuation of our previous studies on the production of acidic ionic-liquid catalysts in which a $\mathrm{SO}_{3} \mathrm{H}$ group bonded to a tertiary amine or heterocyclic nitrogen [7-10], we prepared a novel member of this attractive class of ionic liquids namely triethylaminium- $N$ sulfonic acid trifluoroacetate $\{[$ TEASA] [TFA] , according to Scheme 1.

The novel ionic liquid was characterized by studying its ${ }^{1} \mathrm{H}$ and ${ }^{13} \mathrm{C}$ NMR, FT-IR, and mass spectroscopic data. In the ${ }^{1} \mathrm{H}$ NMR spectrum of [TEASA][TFA] (Figure 1), the peaks related to 9 hydrogens of the three $\mathrm{CH}_{3}$ groups, and 6 hydrogens of the three $\mathrm{CH}_{2}$ groups have appeared at 1.19 (as triplet) and 3.11 (as quartet) ppm, respectively. The acidic hydrogen of $\mathrm{SO}_{3} \mathrm{H}$ has appeared at 10.00 (as broad) ppm. The ${ }^{13} \mathrm{C}$ NMR spectrum of the ionic liquid (Figure 2) showed 4 peaks. The peaks observed at 8.7 and $46.3 \mathrm{ppm}$ correspond to the $\mathrm{CH}_{3}$ and $\mathrm{CH}_{2}$ carbons of cation moiety, correspondingly. The two

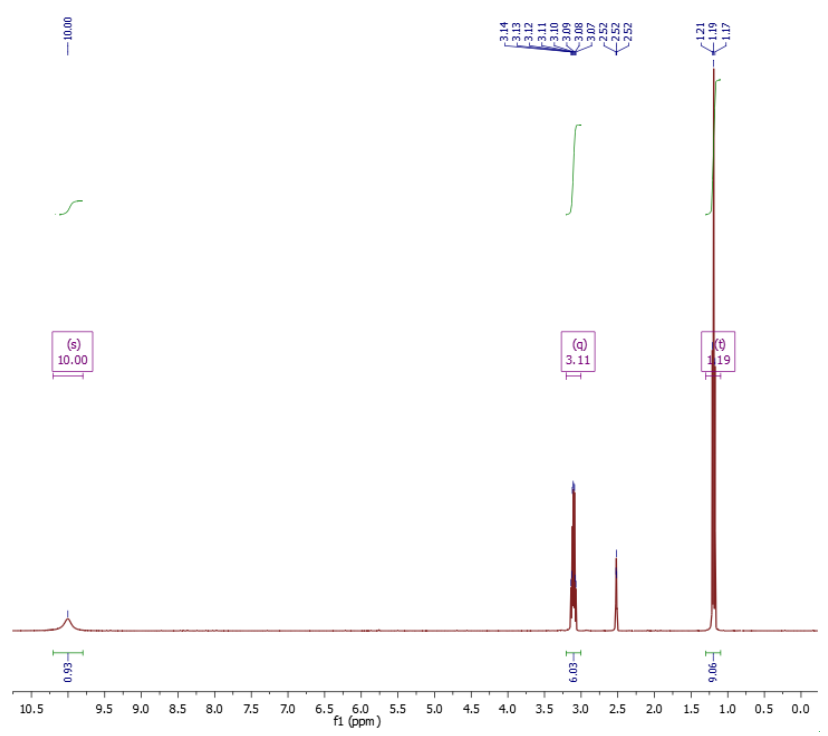

Figure 1. The ${ }^{1} \mathrm{H} \quad \mathrm{NMR}$ spectrum of [TEASA][TFA]

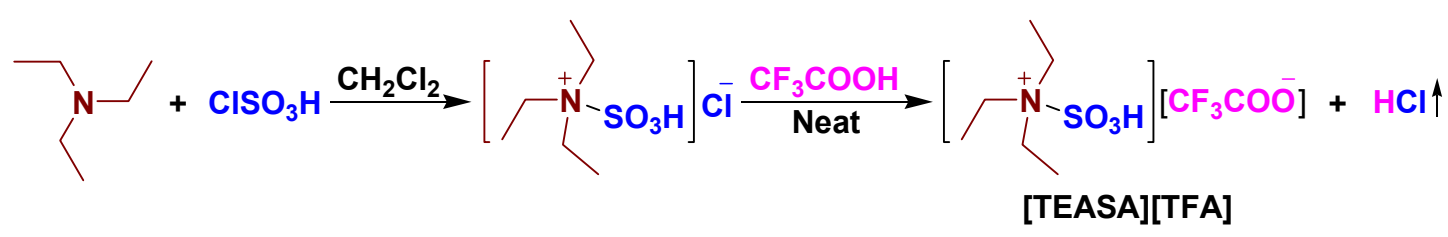

Scheme 1. The production of [TEASA][TFA] 
quartet peaks observed at 115.4 and $158.8 \mathrm{ppm}$ as quartet, are related to the $\mathrm{CF}_{3}$ and $\mathrm{C}=\mathrm{O}$ groups of anion moiety, respectively.

The FT-IR spectrum is shown in Figure 3, and the relevant data are summarized in Table 1. As it can be seen in Figure 3 and Table 1, the peaks related to expected functional groups and bonds in [TEASA][TFA] have presented in the spectrum. The mass spectrum of triethylaminium- $N$-sulfonic acid trifluoroacetate showed the molecular mass $\left(\mathrm{M}^{+}\right)$and $\left(\mathrm{M}^{+}+1\right)$ at $m / z 295$ and 296, correspondingly.

\subsection{Testing catalytic activity of [TEASA] [TFA] for the synthesis of 1- thioamidoalkyl-2-naphthols}

To show the efficient catalytic activity of [TEASA][TFA] to promote organic transformations, at first, the production of 1-thioamidoalkyl-2-naphthols was examined in the presence of this catalyst. Thus, the solventless condensation of 3-nitrobenzaldehyde (1

Table 1. The FT-IR data of [TEASA][TFA]

\begin{tabular}{cl}
\hline Peak $\left(\mathrm{cm}^{-1}\right)$ & Related functional group or bond \\
\hline 852 & Symmetric N-S stretching vibration \\
1068 & S-OH bend \\
1172 and 1291 & Asymmetric and symmetric stretching \\
1229 & and bending of S-O vibrations \\
1709 & $\mathrm{C}-\mathrm{F}$ \\
$2400-3600$ & $\mathrm{OH}$ group of the $\mathrm{SO}_{3} \mathrm{H}$ \\
\hline
\end{tabular}

Table 2. Influence of the catalyst amount and temperature on the reaction of 3nitrobenzaldehyde with 2-naphthol and thioacetamide

\begin{tabular}{ccccc}
\hline No & $\begin{array}{c}\text { Mol\% of the } \\
\text { catalyst }\end{array}$ & $\begin{array}{c}\text { Temp. } \\
\left({ }^{\circ} \mathrm{C}\right)\end{array}$ & $\begin{array}{c}\text { Time } \\
(\mathrm{min})\end{array}$ & $\begin{array}{c}\text { Yield }^{\mathrm{a}} \\
(\%)\end{array}$ \\
\hline 1 & 10 & 80 & 25 & 87 \\
2 & 15 & 80 & 15 & $96^{\mathrm{b}}$ \\
3 & 20 & 80 & 15 & $96^{\mathrm{b}}$ \\
4 & 15 & 70 & 20 & 84 \\
5 & 15 & 90 & 15 & $96^{\mathrm{b}}$ \\
\hline
\end{tabular}

aIsolated yield ; bTLC showed completion of the reaction

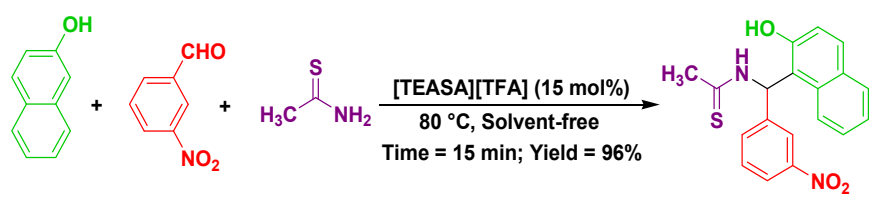

Scheme 2. The optimal conditions for the synthesis of 1-thioamidoalkyl-2-naphthols mmol) with 2-naphthol (1 mmol) and thioacetamide $(1.2 \mathrm{mmol})$ was chosen as a model reaction (Scheme 2 ), and influence of the catalyst amount and temperature on it was studied. The main results are summarized in Table 2. As the data in this table indicate, the best results were observed when $15 \mathrm{~mol} \%$ of the catalyst was used at $80{ }^{\circ} \mathrm{C}$ (entry 2 ).

After the reaction was optimized in terms of the catalyst amount and temperature, various arylaldehydes were reacted with 2-naphthol and thioacetamide; the corresponding results are shown in Table 3. As it is shown in this Table, the catalyst was highly effective and general for the reaction; all functional groups on different positions of the arylaldehydes afforded the respective of 1-thioamidoalkyl-2naphthols in excellent yields and in short reaction times.

In a plausible mechanism (Scheme 3), which supported by the literature [19,23,24], at first, 2 -naphthol is added to the activated aldehyde by the acidic hydrogen of [TEASA] [TFA] to give I; trifluoroacetate anion of the catalyst also helps to the nucleophilic addition. Removing a molecule of $\mathrm{H}_{2} \mathrm{O}$ from intermediate I, by helping the catalyst, affords II. Intermediate II is activated by the catalyst, and then, acetamide

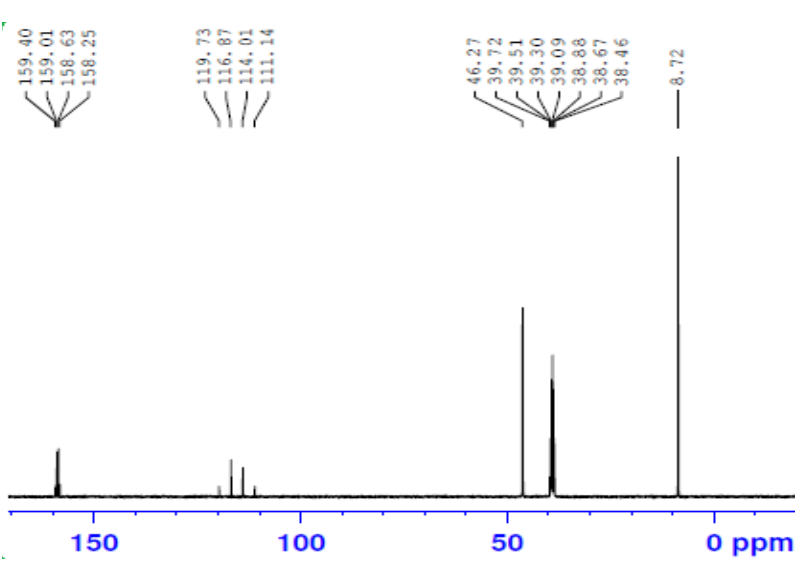

Figure 2. The ${ }^{13} \mathrm{C}$ NMR spectrum of the catalyst

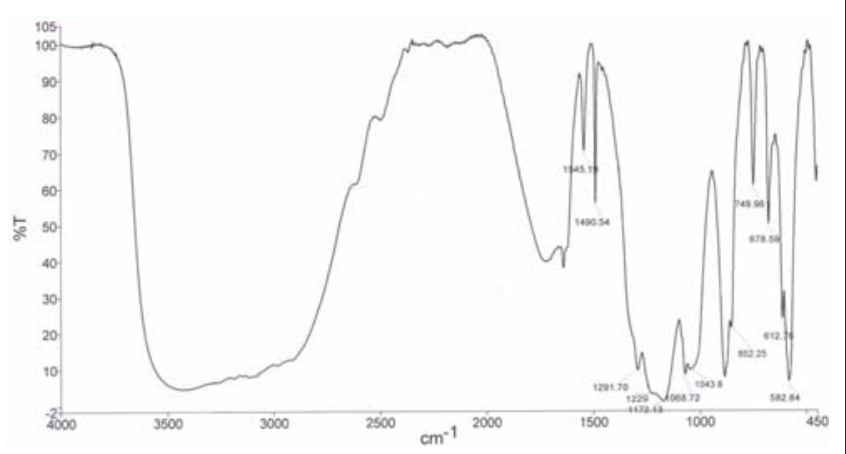

Figure 3. The IR spectrum of [TEASA][TFA] 
is added to it to give the respective 1-thioamidoalkyl-2-naphthol.

\subsection{Testing catalytic activity of [TEASA] \\ [TFA] for the synthesis of 14-aryl-14H- dibenzo $[a, j]$ xanthenes}

After the successful application of [TEASA][TFA] for the production of 1-thioamidoalkyl-2-naphthols, its catalytic activity was checked for the synthesis of 14-aryl$14 H$-dibenzo[ $a, j]$ xanthenes. For this purpose, 3 -nitrobenzaldehyde (1 $\mathrm{mmol})$ was reacted with 2 -naphthol (2 mmol) (Scheme 4 ) in the presence of various mol percentages of the ionic liquid at different temperatures. The main results are displayed in Table 4. According to the reported results in this Table, the most suitable catalyst amount and temperature were $15 \mathrm{~mol} \%$ and $100^{\circ} \mathrm{C}$, respectively (entry 2 ).

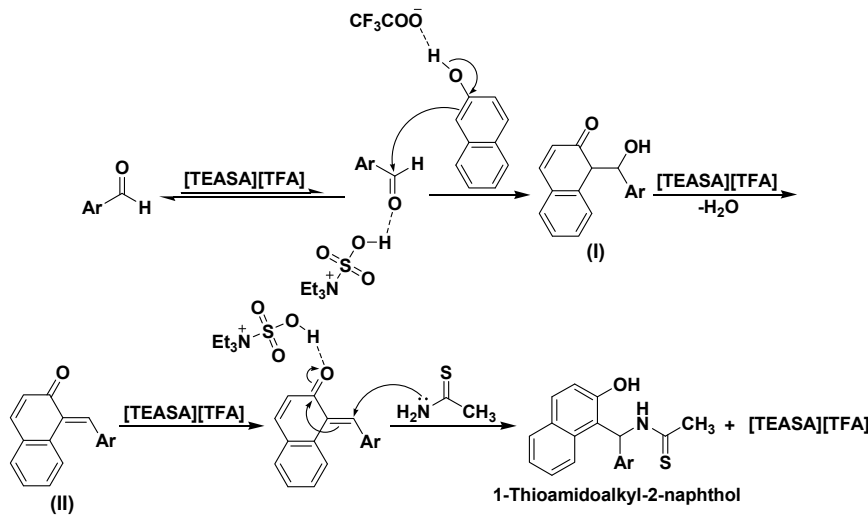

Scheme 3. The proposed mechanism for the 1-thioamidoalkyl-2-naphthols synthesis
After that, various arylaldehydes (bearing electron-attracting, electron-releasing and halogen substituents) were reacted with 2 -naphthol in the optimized conditions. The respective results are summarized in Table 5. As it can be seen in this Table, [TEASA][TFA] has successfully catalyzed the reactions, and gave 14-aryl-14H-dibenzo[ $a, j]$ xanthenes in high yields and in short reaction times. Thus, [TEASA][TFA] was also highly effective and general catalyst for the production of 14-aryl$14 H$-dibenzo[ $a, j]$ xanthenes. According to the

Table 4. Effect of the catalyst amount and temperature on the reaction of 3-nitrobenzaldehyde with 2-naphthol

\begin{tabular}{ccccc}
\hline Entry & $\begin{array}{c}\text { Mol\% of the } \\
\text { catalyst }\end{array}$ & $\begin{array}{c}\text { Temp. } \\
\left({ }^{\circ} \mathrm{C}\right)\end{array}$ & $\begin{array}{c}\text { Time } \\
(\mathrm{min})\end{array}$ & $\begin{array}{c}\text { Yield }^{\mathrm{a}} \\
(\%)\end{array}$ \\
\hline 1 & 10 & 100 & 30 & 79 \\
2 & 15 & 100 & 10 & $97 \mathrm{~b}$ \\
3 & 20 & 100 & 10 & $97 \mathrm{~b}$ \\
4 & 15 & 90 & 25 & 89 \\
5 & 15 & 110 & 10 & $97^{\mathrm{b}}$ \\
\hline aIsolated yield; bTLC showed completing the reaction.
\end{tabular}

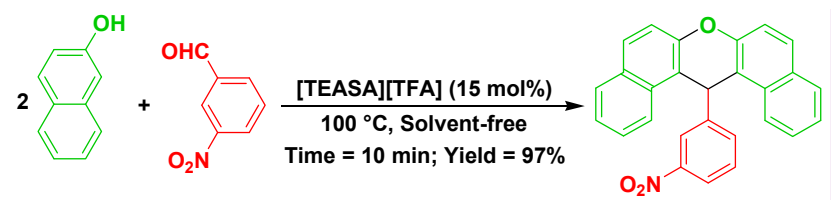

Scheme 4. The optimized conditions for the preparation of 4 -aryl14- $H$-dibenzo[a,j]xanthenes

Table 3. [TEASA][TFA] catalyzed the synthesis of 1-thioamidoalkyl-2-naphthols from arylaldehydes, 2-naphthol and thioacetamide

\begin{tabular}{cccccc}
\hline \multirow{2}{*}{ Entry } & \multirow{2}{*}{ Aldehyde } & Time $(\mathrm{min})$ & Yield $^{\mathrm{a}}(\%)$ & \multicolumn{2}{c}{ M.P. $\left({ }^{\circ} \mathrm{C}\right)$} \\
\cline { 5 - 6 } & & & & Found & Reported \\
\hline 1 & $\mathrm{C}_{6} \mathrm{H}_{5} \mathrm{CHO}$ & 20 & 94 & $184-186$ & $185-187[19]$ \\
3 & $3-\mathrm{O}_{2} \mathrm{NC}_{6} \mathrm{H}_{4} \mathrm{CHO}$ & 15 & 96 & $231-233$ & $234-236[23]$ \\
4 & $2-\mathrm{O}_{2} \mathrm{NC}_{6} \mathrm{H}_{4} \mathrm{CHO}$ & 25 & 89 & $228-231$ & $229-231[23]$ \\
5 & $4-\mathrm{O}_{2} \mathrm{NC}_{6} \mathrm{H}_{4} \mathrm{CHO}$ & 15 & 96 & $238-240$ & $243-245[24]$ \\
6 & $4-\mathrm{FC}_{6} \mathrm{H}_{4} \mathrm{CHO}$ & 30 & 93 & $200-202$ & $203-205[19]$ \\
7 & $2-\mathrm{BrC}_{6} \mathrm{H}_{4} \mathrm{CHO}$ & 20 & 91 & $232-234$ & - \\
8 & $4-\mathrm{BrC}_{6} \mathrm{H}_{4} \mathrm{CHO}$ & 15 & 94 & $192-194$ & $195-196[19]$ \\
9 & $3-\mathrm{ClC}_{6} \mathrm{H}_{4} \mathrm{CHO}$ & 30 & 92 & $257-259$ & $256-258[19]$ \\
10 & $4-\mathrm{ClC}_{6} \mathrm{H}_{4} \mathrm{CHO}$ & 20 & 90 & $240-242$ & $240-242[25]$ \\
11 & $2,4-\mathrm{Cl}_{2} \mathrm{C}_{6} \mathrm{H}_{3} \mathrm{CHO}$ & 40 & 87 & $216-218$ & $219-221[19]$ \\
12 & $4-\mathrm{CH}_{3} \mathrm{C}_{6} \mathrm{H}_{4} \mathrm{CHO}$ & 30 & 94 & $183-185$ & $180-183[20]$ \\
\hline
\end{tabular}

a Isolated yield \{(Actual amount of product in gram/Theoretical amount of product in gram) $\times 100\}$ 
above results, we think that the ionic liquid can catalyze organic reactions which need to acidic catalyst.

In a proposed mechanism (Scheme 5), which supported by the literature [33,39], initially 2 -naphthol is added to the activated aldehyde

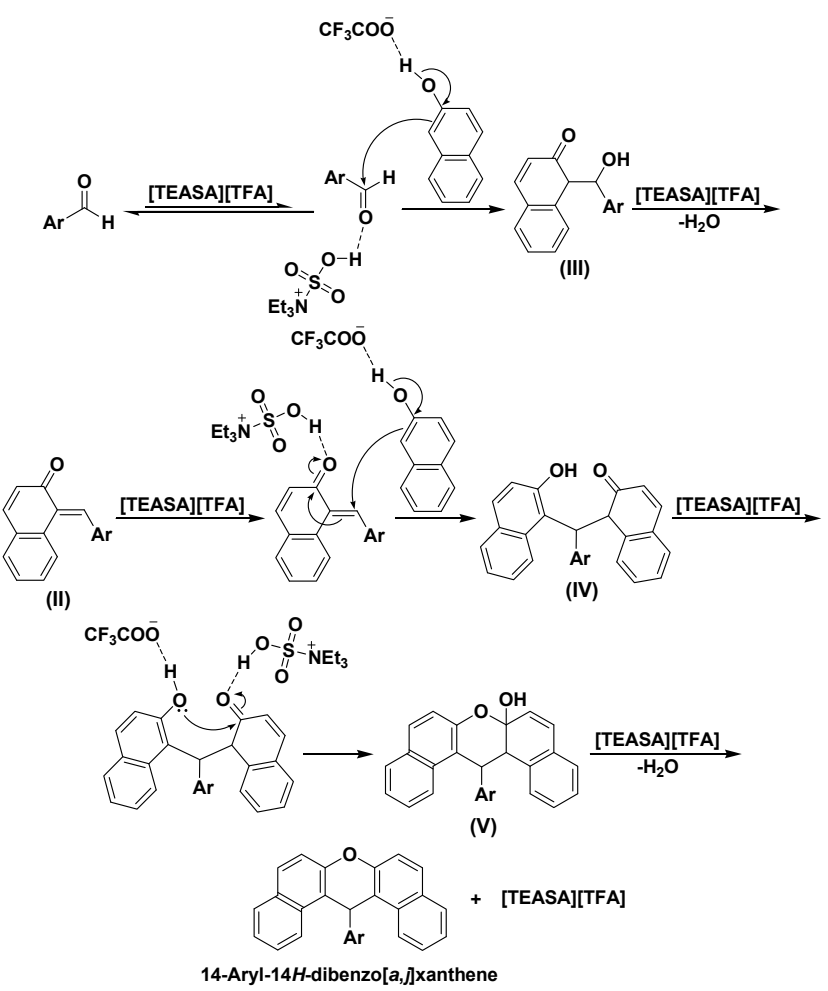

Scheme 5. The proposed mechanism for the production of 4-aryl-14H-dibenzo[a,j]xanthenes by the acidic catalyst to afford III. Removing a $\mathrm{H}_{2} \mathrm{O}$ molecule from III, by helping [TEASA][TFA], gives II. Then, intermediate II is activated by the catalyst, and another molecule of 2-naphthol is added to it to afford IV. Intermediate IV converts to $\mathbf{V}$ by helping the cation and anion of [TEASA][TFA]. Finally, a molecule of $\mathrm{H}_{2} \mathrm{O}$ is removed from $\mathbf{V}$ to produce 14-aryl-14H-dibenzo[a,j]xanthene.

\section{Conclusions}

In conclusion, we have developed a novel $\mathrm{SO}_{3} \mathrm{H}$-containing ionic-liquid catalyst for the synthesis of 1-thioamidoalkyl-2-naphthols and 14-aryl-14H-dibenzo[a,j]xanthenes. The benefits of application of [TEASA] [TFA] to promote these reactions consist of: effectiveness, generality, higher yields and milder reaction conditions compared with most of the reported methods, short reaction times, simple preparation and operation of the catalyst, production of the catalyst from available and inexpensive starting materials, clean procedure, easy workup, and achieving the reactions in solvent-free conditions.

\section{Acknowledgment}

We thank Research Council of Payame Noor University for the partial support of this work.

Table 5. The synthesis of 14-aryl-14H-dibenzo[a,j]xanthenes from arylaldehydes and 2-naphthol using [TEASA][TFA]

\begin{tabular}{cccccc}
\hline \multirow{2}{*}{ Entry } & \multirow{2}{*}{ Aldehyde } & Time $(\mathrm{min})$ & Yield ${ }^{\mathrm{a}}(\%)$ & \multicolumn{2}{c}{ M.p. $\left({ }^{\circ} \mathrm{C}\right)$} \\
\cline { 4 - 6 } & & & & Found & Reported \\
2 & $\mathrm{C}_{6} \mathrm{H}_{5} \mathrm{CHO}$ & 20 & 96 & $186-188$ & $184-185[38]$ \\
3 & $3-\mathrm{O}_{2} \mathrm{NC}_{6} \mathrm{H}_{4} \mathrm{CHO}$ & 10 & 97 & $210-212$ & $210-211[39]$ \\
4 & $2-\mathrm{NO}_{2} \mathrm{C}_{6} \mathrm{H}_{4} \mathrm{CHO}$ & 25 & 93 & $211-213$ & $212-214[36]$ \\
5 & $4-\mathrm{NO}_{2} \mathrm{C}_{6} \mathrm{H}_{4} \mathrm{CHO}$ & 15 & 98 & $310-311$ & $310[32]$ \\
6 & $2-\mathrm{ClC}_{6} \mathrm{H}_{4} \mathrm{CHO}$ & 40 & 95 & $216-218$ & $215-216[32]$ \\
7 & $3-\mathrm{ClC}_{6} \mathrm{H}_{4} \mathrm{CHO}$ & 25 & 98 & $205-206$ & $207-209[33]$ \\
8 & $4-\mathrm{ClC}_{6} \mathrm{H}_{4} \mathrm{CHO}$ & 15 & 89 & $291-293$ & $288-289[39]$ \\
9 & $3-\mathrm{BrC}_{6} \mathrm{H}_{4} \mathrm{CHO}$ & 20 & 97 & $189-191$ & $187-189[36]$ \\
10 & $4-\mathrm{BrC}_{6} \mathrm{H}_{4} \mathrm{CHO}$ & 10 & 95 & $294-296$ & $296[32]$ \\
11 & $4-\mathrm{CH}_{3} \mathrm{OC}_{6} \mathrm{H}_{4}$ & 45 & 94 & $204-206$ & $203-205[38]$ \\
\hline
\end{tabular}

a Isolated yield \{(Actual amount of product in gram/Theoretical amount of product in gram $) \times 100$ \} 


\section{References}

[1] Wasserscheid, Welton, P. T. (2008). Ionic Liquids in Synthesis, Wiley-VCH, Weinheim.

[2] Sangian, H.F., Kristian, J., Rahma, S., Dewi, H., Puspasari, D., Agnesty, S., Gunawan, S., Widjaja, A. (2015). Preparation of Reducing Sugar Hydrolyzed from High-Lignin Coconut Coir Dust Pretreated by the Recycled Ionic Liquid [mmim][dmp] and Combination with Alkaline. Bulletin of Chemical Reaction Engineering \& Catalysis, 10: 8-22.

[3] Honarmand, M., Esmaeili, E. (2017). Tris(hydroxymethyl)methane ammonium hydrogensulphate as a nano ionic liquid and its catalytic activity in the synthesis of bis(indolyl)methanes. Journal of Molecular Liquids, 225: 741-749

[4] Roslan, N.A., Che Hasnan, M.H., Abdullah, N., Abdullah, S.B., Abidin, S.Z. (2016). A Preliminary Study: Esterification of Free Fatty Acids (FFA) in Artificially Modified Feedstock Using Ionic Liquids as Catalysts. Bulletin of Chemical Reaction Engineering \& Catalysis, 11: 182-190.

[5] Caldas, B.S., Nunes, C.S., Souza, P.R., Rosa, F.A., Visentainer, J.V., Júnior, O.de O.S., Muniz, E.C. (2016). Supercritical ethanolysis for biodiesel production from edible oil waste using ionic liquid [HMim] $\left[\mathrm{HSO}_{4}\right]$ as catalyst. Applied Catalysis B: Environmental, 181: 289297.

[6] Fareghi-Alamdari, R., Nadiri Niri, M., Hazarkhani, H. (2017). Synthesis and characterization of a new hydroxyl functionalized diacidic ionic liquid as catalyst for the preparation of diester plasticizers. Journal of Molecular Liquids, 227: 153-160.

[7] Zolfigol, M.A., Khazaei, A., Moosavi-Zare, A.R., Zare, A., Kruger, H.G., Asgari, Z., Khakyzadeh, V., Kazem-Rostami, M. (2012). Design of Ionic Liquid 3-Methyl-1-sulfonic Acid Imidazolium Nitrate as Reagent for the Nitration of Aromatic Compounds by in Situ Generation of $\mathrm{NO}_{2}$ in Acidic Media. Journal of Organic Chemistry, 77: 3640-3645.

[8] Zare, A., Moosavi-Zare, A.R., Merajoddin, M., Zolfigol, M.A., Hekmat-Zadeh, T., Hasaninejad, A., Khazaei, A., Mokhlesi, M., Khakyzadeh, V., Derakhshan-Panah, F., Beyzavi, M.H., Rostami, E., Arghoon, A., Roohandeh, R. (2012). Ionic liquid triethylamine-bonded sulfonic acid $\left\{\left[\mathrm{Et}_{3} \mathrm{~N}-\mathrm{SO}_{3} \mathrm{H}\right] \mathrm{Cl}\right\}$ as a novel, highly efficient and homogeneous catalyst for the synthesis of 8 -acetamido ketones, 1,8dioxo-octahydroxanthenes and 14-aryl-14Hdibenzo[a,j]xanthenes. Journal of Molecular Liquids, 167: 69-77.
[9] Zare, A., Nasouri, Z. (2016). A green approach for the synthesis of 3,4-dihydropyrimidin-2(1H)-ones (and -thiones) using $N, N$-diethyl- $N$ sulfoethanaminium hydrogen sulfate. Journal of Molecular Liquids, 216: 364-369.

[10] Moosavi-Zare, A. R., Zolfigol, M.A., Zarei, M., Zare, A., Khakyzadeh, V., Hasaninejad, A. (2013). Design, characterization and application of new ionic liquid 1-sulfopyridinium chloride as an efficient catalyst for tandem Knoevenagel-Michael reaction of 3-methyl-1phenyl-1H-pyrazol-5(4H)-one with aldehydes. Applied Catalysis A: General, 467: 61-68.

[11] Vaddula, B.R., Varma, R.S., Leazer, J. (2013). Mixing with microwaves: solvent-free and catalyst-free synthesis of pyrazoles and diazepines. Tetrahedron Letters, 54: 1538-1541.

[12] Rana, S., Jonnalagadda, S.B. (2017). Synthesis and characterization of amine functionalized graphene oxide and scope as catalyst for Knoevenagel condensation reaction. Catalysis Communications, 92: 31-34.

[13] Himaja, M., Poppy, D., Asif, K. (2011). Green technique-solvent free synthesis and its advantages. International Journal of Research in Ayurveda \& Pharmacy, 2: 1079-1086.

[14] Shen, A.Y., Tsai, C.T., Chen, C.L. (1999). Synthesis and cardiovascular evaluation of $\mathrm{N}$-substituted 1-aminomethyl-2-naphthols. European Journal of Medicinal Chemistry, 34: 877-882.

[15] Gyemant, N., Engi, H., Schelz, Z., Szatmari, I., Toth, D., Fulop, F., Nar, J.M., Witte, P.D. (2010). In vitro and in vivo multidrug resistance reversal activity by a Betti-base derivative of tylosin. British Journal of Cancer, 103: 178-185.

[16] Kidwai, M., Chauhan, R. (2013). Catalyst-free Synthesis of Betti bases in a Mannich-Type Reaction. Asian Journal of Organic Chemistry, 2: 395-398.

[17] Wei, H.-X., Lu, D., Sun, V., Zhang, J., Gu, Y., Osenkowski, P., Ye, W., Selkoe, D.J., Wolfe, M.S., Augelli-Szafran, C.E. (2016). Part 2. Notch-sparing Y-secretase inhibitors: The study of novel $\mathrm{Y}$-amino naphthyl alcohols. Bioorganic and Medicinal Chemistry Letters, 26: 2133-2137.

[18] Zhang, Z.-P., Wen, J.-M., Li, J.-H., Hu, W.-X. (2009). One-pot synthesis of thiocarbamidoalkyl naphthols. Journal of Chemical Research, 3: 162-164.

[19] Khazaei, A., Abbasi, F., Moosavi-Zare, A.R. (2015). Catalytic application of N,2-dibromo6 - c h l o r o - 3, 4 - d i h y d r o $2 H$ benzo[e] $[1,2,4]$ thiadiazine- 7 -sulfonamide 1,1-dioxide on the synthesis of 1-carbamato- 
alkyl-2-naphthols and 1-thioamido-alkyl-2naphthols. Journal of Sulfur Chemistry, 36: 364-372.

[20] Zare, A., Kaveh, H., Merajoddin, M., MoosaviZare, A.R., Hasaninejad, A., Zolfigol, M.A. (2013). Saccharin sulfonic acid (SASA) as a highly efficient catalyst for the condensation of 2-naphthol with arylaldehydes and amides (thioamides and alkyl carbamates) under green, mild and solvent-free conditions. Phosphorus, Sulfur and Silicon, and the Related Elements, 188: 573-584.

[21] Zare, A., Akbarzadeh, S., Foroozani, E., Kaveh, H., Moosavi-Zare, A.R., Hasaninejad, A., Mokhlesi, M., Beyzavi, M.H., Zolfigol, M.A. (2012). Triethylamine-bonded sulfonic acid $\left(\left[\mathrm{Et}_{3} \mathrm{~N}-\mathrm{SO}_{3} \mathrm{H}\right] \mathrm{Cl}\right)$ : a highly efficient and homogeneous catalyst for the condensation of 2-naphthol with arylaldehydes and amides (alkyl carbamates or thioamides). Journal of Sulfur Chemistry, 33: 259-272.

[22] Kantevari, S., Vuppalapati, S.V.N., Nagarapu, L. (2007). Montmorillonite K10 catalyzed efficient synthesis of amidoalkyl naphthols under solvent free conditions. Catalysis Communications, 8: 1857-1862.

[23] Hassanabadi, A., Hosseini-Tabatabaei, M.R. (2012). A three-component novel synthesis of 1-[aryl(thioacetamido)methyl]-2-naphthol derivatives. Journal of Chemical Research, 510511.

[24] Eshghi, H., Zohuri, G.H., Damavandi, S. (2012). Synthesis of novel thioamidoalkyland thiocarbamidoalkyl naphthols via a three-component condensation reaction using heterogeneous catalyst of ferric hydrogensulfate. Synthetic Communications, 42: 516-525.

[25] Ghorbani-Choghamarani, A., Rashidimoghadam, S. (2015). 1,3-Dibromo-5,5dimethylhydantoin as an efficient catalyst for synthesis of thioamidoalkyl and bis(thio)amidoalkyl-2-naphthols under solvent-free conditions. Research on Chemical Intermediates, 41: 6271-6281.

[26] Jamison, J.M., Krabill, K., Hatwalkar, A., Jamison, E., Tsai, C. (1990). Potentiation of the antiviral activity of poly r(A-U) by xanthene dyes. Cell Biology International Reports, 14: 1075-1084.

[27] Hideo, T. (1981). Benzopyrano[2,3-b]xanthene Derivatives. Jpn. Tokkyo Koho JP, 56005480, Chemical Abstract, 95: 80922b.

[28] Poupelin, J.P., Saint-Ruf, G., FoussardBlanpin, O., Narcisse, G., Uchida-Ernouf, G., Lacroix, R. (1978). Synthesis and antiinflammatory properties of bis (2-hydroxy-1naphthyl)methane derivatives I. European Journal of Medicinal Chemistry, 13: 67-71.
[29] Knight, C.G., Stephens, V. (1989). XantheneDye-Labelled Phosphatidylethanolamines as Probes of Interfacial pH. Studies in Phospholipid Vesicles. Biochemical Journal, 258: 683387.

[30] Ion, R.M., Frackowiak, D., Wiktorowicz, P.K. (1998). The incorporation of various porphyrins into blood cells measured via flow cytometry, absorption and emission spectroscopy. Acta Biochimica Polonica, 45: 833-845.

[31] Ahmad, M., King, T.A., Cha, B.H., Lee, J. (2002). Performance and Photostability of Xanthene and Pyrromethene Laser Dyes in Sol-Gel Phases. Journal of Physics D: Applied Physics, 35: 1473-1476.

[32] Pasha, M.A., Jayashankara, V.P. (2007). Molecular iodine catalyzed synthesis of aryl$14 H$-dibenzo[ $a, j]$ xanthenes under solvent-free condition. Bioorganic and Medicinal Chemistry Letters, 17: 621-623.

[33] Zolfigol, M.A., Moosavi-Zare, A.R., Arghavani-Hadi, P., Zare, A., Khakyzadeh, V., Darvishi, G. (2012). $\mathrm{WCl}_{6}$ as an efficient, heterogeneous and reusable catalyst for the preparation of 14-aryl-14H-dibenzo[a,j]xanthenes with high TOF. RSC Advances, 2: 3618-3620.

[34] Safari, J., Aftabi, P., Ahmadzadeh, M., Sadeghi, M., Zarnegar, Z. (2017). Sulfonated starch nanoparticles: An effective, heterogeneous and bio-based catalyst for synthesis of 14-aryl-14-H-dibenzo[a,j]xanthenes, Journal of Molecular Structure, 1142: 33-39.

[35] Bartolomeu, A.A., Menezes, M., Filho, L.S. (2014). Efficient one-pot synthesis of 14-aryl$14 \mathrm{H}$-dibenzo[a,j]xanthene derivatives promoted by niobium pentachloride, Chemical Papers, 68: 1593-1600.

[36] Zare, A., Merajoddin, M., Abi, F., MoosaviZare, A.R., Mokhlesi, M., Zolfigol, M.A., Asgari, Z., Khakyzadeh, V., Hasaninejad, A., Khalafi-Nezhad, A., Parhami, A. (2012). Trityl Chloride ( $\mathrm{TrCl}$ ): Efficient and Homogeneous Organocatalyst for the Solvent-Free Synthesis of 14-Aryl-14H-dibenzo[a,j]xanthenes by in situ Formation of Carbocationic System. Journal of the Chinese Chemical Society, 59: 860-865.

[37] Wu, L., Yang, C., Yang, L., Yang, L. (2010). Synthesis of 14-Substituted-14H-Dibenzo[a,j] $\mathrm{X}$ a n thenes and 1,8-DioxoOctahydroxanthenes Using Silica Chloride $\left(\mathrm{SiO}_{2}-\mathrm{Cl}\right)$ Under Solvent-Free Conditions. Phosphorus, Sulfur and Silicon, and the Related Elements, 185: 903-909.

[38] Mirjalili, B.F., Bamoniri, A., Akbari, A., Taghavinia, N. (2011). Nano-TiO ${ }_{2}$ : an ecofriendly and re-usable catalyst for the synthesis of 14-aryl or alkyl-14H-dibenzo [a,j] xanthenes. Journal of the Iranian Chemical Society, 8: S129-S134. 
[39] Moosavi-Zare, A.R., Zolfigol, M.A., Khaledian, O., Khakyzadeh, V. (2014). Condensation of 2naphtol with arylaldehydes using acetic acid functionalized ionic liquids as highly efficient and reusable catalysts. Chinese Journal of Catalysis, 35: 573-578.
[40] Kumar, A., Rout, L., Achary, L.S.K., Dhaka, R.S., Dash, P. (2017). Greener Route for Synthesis of aryl and alkyl-14H-dibenzo [a.j] xanthenes using Graphene Oxide-Copper Ferrite Nanocomposite as a Recyclable Heterogeneous Catalyst. Scientific Reports, 7: 42975. 